\title{
A New Monotypic Genus from the American Southwest to accommodate "Semiothisa" kuschea (Geometridae: Ennominae)
}

\author{
TANNER A. MATSON \\ Department of Ecology and Evolutionary Biology, University of Connecticut, Storrs, Connecticut 06269-3043, USA \\ ”tanner.matson@uconn.edu; (1) https://orcid.org/0000-0001-7560-7294 \\ lsid:zoobank.org:author:AD85C521-0781-451F-92F6-D32B08C21395
}

\begin{abstract}
The monotypic Metrica new genus is described for Metrica kuschea (Guedet, 1939) new combination. The genus is placed in the tribe Ennomini Duponchel and hypothesized to be most closely related to a Neotropical species of "Isochromodes" Warren. Adult morphology, including male and female genitalia are illustrated, and molecular data supporting the transfer of "Semiothisa" kuschea (Macariini Guenée) to the Ennomini are presented.
\end{abstract}

Key words: Arizona, Chiricahua Mountains, climate change, Erigeron, Madrean, sky island

\section{Introduction}

A new genus is proposed for a distinct and uncommon ennomine geometrid, Semiothisa kuschea Guedet, known only from the upper elevations of the Chiricahua Mountains of southeastern Arizona, USA, but perhaps also inhabiting the northern reaches of Mexico's Sierra Madre Occidental. This taxon is long known to be misplaced - both with respect to its generic and Macariini tribal placement. Ferguson (1983, p. 90) lists kuschea as "mispl." in his North American checklist; and later, in his monograph of North American Macariini (Ferguson 2008), he excludes this taxon altogether from the Macariini. In his world catalog of the Geometridae, Scoble (1999) lists kuschea (and other Semiothisa of questionable association) in "Semiothisa," drawing attention to its problematic status as a member of the genus and tribe. At present, the scope of Semiothisa is limited to a much smaller group of neotropical species based on similarity of male genitalic characters (Inoue 1986; Scoble \& Krüger 2002). Neither Ferguson (2008) or Pohl et al. (2016) list any Semiothisa in North America north of Mexico, although kuschea is still sometimes treated as a valid member of the genus Semiothisa (e.g., Moth Photographer's Group, 2021).

Newly acquired molecular data and its placement in the Ennomini distant to the Macariini, spurred the description of this monotypic genus. Nuclear and mitochondrial markers suggest Metrica kuschea represents a distinct ennomine lineage most closely related to a species of Neotropical "Isochromodes," which itself appears to represent a new genus. Below, I provide a description and illustrations of adult Metrica kuschea, including its male and female genitalia. Additionally, I present a preliminary assessment of the phylogenetic position of Metrica and related genera.

\section{Methods}

The diagnosis and description of Metrica is based on six pinned specimens of Metrica kuschea from the collections of the National Museum of Natural History (USNM), Washington DC; California Academy of Sciences (CAS), San Francisco, CA; and the personal collection of John D. Palting (JDP), Tucson, AZ. Four genitalic dissections were studied: two prepared previously from type material $(1 \hat{\partial}, 1$ ) $)$ and two $(1 \hat{\delta}, 1 \rho)$ prepared by the author following the methods described in Lafontaine (2004). Preparations were stained with Eosin-Y or chlorazol black and slide-mounted in Euparal. Images were taken using a Visionary Digital imaging system and images manipulated (background removed) with Adobe Photoshop (Adobe Systems, Mountain View, CA). 
Voucher TAM0223 was chosen for DNA sequencing. Seven single-copy genes commonly used to resolve phylogenetic relationships of Lepidoptera were sequenced: cytochrome oxidase subunit 1 (CO1) from the mitochondrial genome, and elongation factor 1 alpha (EF-1 $\alpha$ ), glyceraldehyde 3-phosphate dehydrogenase(GAPDH), isocitrate dehydrogenase (IDH), cytosolic malate dehydrogenase (MDH), wingless (wgl), and ribosomal protein S5 (RpS5) from the nuclear genome (Wahlberg and Wheat 2008; Sihvonen et al. 2011; Õunap et al. 2016; Wahlberg et al. 2016; Murillo-Ramos et al. 2019). Both CO1 and EF-1 $\alpha$ were sequenced in two parts. DNA extractions were performed using the protocol and material from Macherey Nagel's (Düren, Germany) NucleoSpin Tissue 250 kit. A single leg was taken from voucher TAM0223 for DNA extraction. Once extracted, DNA was stored in a $\sim 4{ }^{\circ} \mathrm{C}$ refrigerator until needed for PCR. PCR profiles and primers outlined in Wahlberg and Wheat (2008) were used. PCR products were sent to Eurofins Genomics (Louisville, KY) for sequencing. Sequence chromatograms were visually inspected for base call errors and heterozygous loci in Geneious v. 2019.2 (Kearse et al. 2012). Sequences were then exported to FASTA files and visually aligned to reference lepidopteran sequences for each locus using AliView v. 1.18 (Larsson 2014). Aligned sequences were uploaded to VoSeq (Peña \& Malm 2012) and GenBank (accession numbers: OM160578, OM180002-OM180007).

A concatenated DNA sequence alignment containing (TAM0223), and the 151 Ennomini taxa and 14 outgroup taxa of Murillo-Ramos et al.'s (2019) geometrid data set were generated and downloaded from VoSeq. The dataset of Murillo-Ramos et al. (2019) contained the additional nuclear protein-coding DNA markers of Arginine Kinase (ArgK), sarco/endoplasmic reticulum calcium ATPase (Ca-ATPase), sorting nexin-9-like protein (Nex9), and carbamoylphosphate synthetase (CAD) that were not sequenced for Metrica kuschea. Thus, the final data set and analyses included both the seven genes sequenced for Metrica kuschea and the additional genes mentioned above for a total of eleven genes with a concatenated length of $7662 \mathrm{bp}$.

Phylogenetic analysis settings also followed Murillo-Ramos et al. (2019). A maximum likelihood analysis was implemented with data partitioned by gene and codon position using IQ-TREE v.1.6.10 (Nguyen et al., 2015). Best-fitting substitution models for the partitioned IQ-TREE analysis were selected using the TESTNEWMERGE option. Each partition was allowed its own evolutionary rate using the -spp option. Support for nodes were evaluated with 1000 ultrafast bootstrap (UFBoot2) approximations (Hoang et al. 2017) and SH-like approximate likelihood ratio test (Guindon et al. 2010) as implemented in IQ-TREE; the -bnni option was used to reduce the overestimation of support. To confirm the topology of the IQ-TREE analysis, a second RAxML analysis (Stamatakis 2014) was carried out using the GTR+CAT option with 1000 rapid bootstraps (RBS) (Stamatakis et al. 2008) - this analysis and subsequent tree are not figured as they agree with the results of the IQ-TREE analysis. All phylogenetic analyses were performed on the CIPRES web server (Miller et al. 2010). Trees were visualized and edited in FigTree v1.4.4 software (Rambaut 2012) and Adobe Photoshop. The final trees were rooted with the same non-geometrid outgroup species as Murillo-Ramos et al. (2019).

\section{Metrica Matson, new genus}

(Figs. 1, 5, 6, 9)

http://zoobank.org:act:51F6B103-5D49-4246-AC0F-E2AE1C7E4C9F

Type Species: Metrica kuschea, original designation, monotypy.

Diagnosis. As the genus is so far monotypic, diagnostic characters entirely match those of the only species. The taxonomic identity of Metrica's closest known relative is uncertain (Fig. 7, see Discussion), though the two taxa are so different as to not warrant confusion. In North America, Metrica is superficially similar to Euaspilates spinataria Packard (Fig. 3) or Eriplatymetra coloradaria (Grote \& Robinson) (Fig. 4) and Eriplatymetra lentifluata Barnes \& McDunnough. Metrica males have filiform antennae, those of the previous species are bipectinate. Metrica lacks the darkened, costobasal gray patch present on the forewing of Euaspilates spinataria, and so far as known, the two moths are wholly allopatric; Metrica kuschea is confined to the Madrean sky islands and Euaspilates spinataria is a Rocky Mountain taxon with a range that extends into western Kansas and Nebraska. Eriplatymetra coloradaria and E. lentifluata lack the darkened subterminal and marginal bands of the forewing found in Metrica. In superficial aspect, Metrica kuschea may also appear similar to the Old World Megaspilates mundataria (Stoll) (Fig. 2), though the two species do not appear to be closely related and do not overlap in range.

In North America north of Mexico, the genitalia of Metrica appear close to those of Caripeta and kin. Metrica 
exhibits a single, elongate, left-directed (right in ventral image view) juxtal+annular extension (the furca) that bows posteriorly toward the fused distal lobes of the gnathos; in this way, much like North American Caripeta. While Metrica has much reduced, sclerotized, fused distal lobes of the gnathos bearing only slight spination, the distal lobes of Caripeta are quite large and densely spinate. Most species of Caripeta have a dense patch of small cornuti, in Metrica, cornuti appear to be absent. In female Metrica, the large ventral flap created by the folded sternite of A8 is more or less symmetric over a centered ostium, yet in Caripeta this flap is often asymmetric with the right portion (left in ventral image view) of the flap rounded and more developed opposite a left-directed ostium. Metrica, Caripeta, and related Ennomini genera have swollen hindtibiae bearing a rosette of long androconia that fold into a longitudinal groove on the mesal surface - although at what level this character will prove to be phylogenetically informative is not yet known. The genetic data published herein also readily diagnose this taxon.

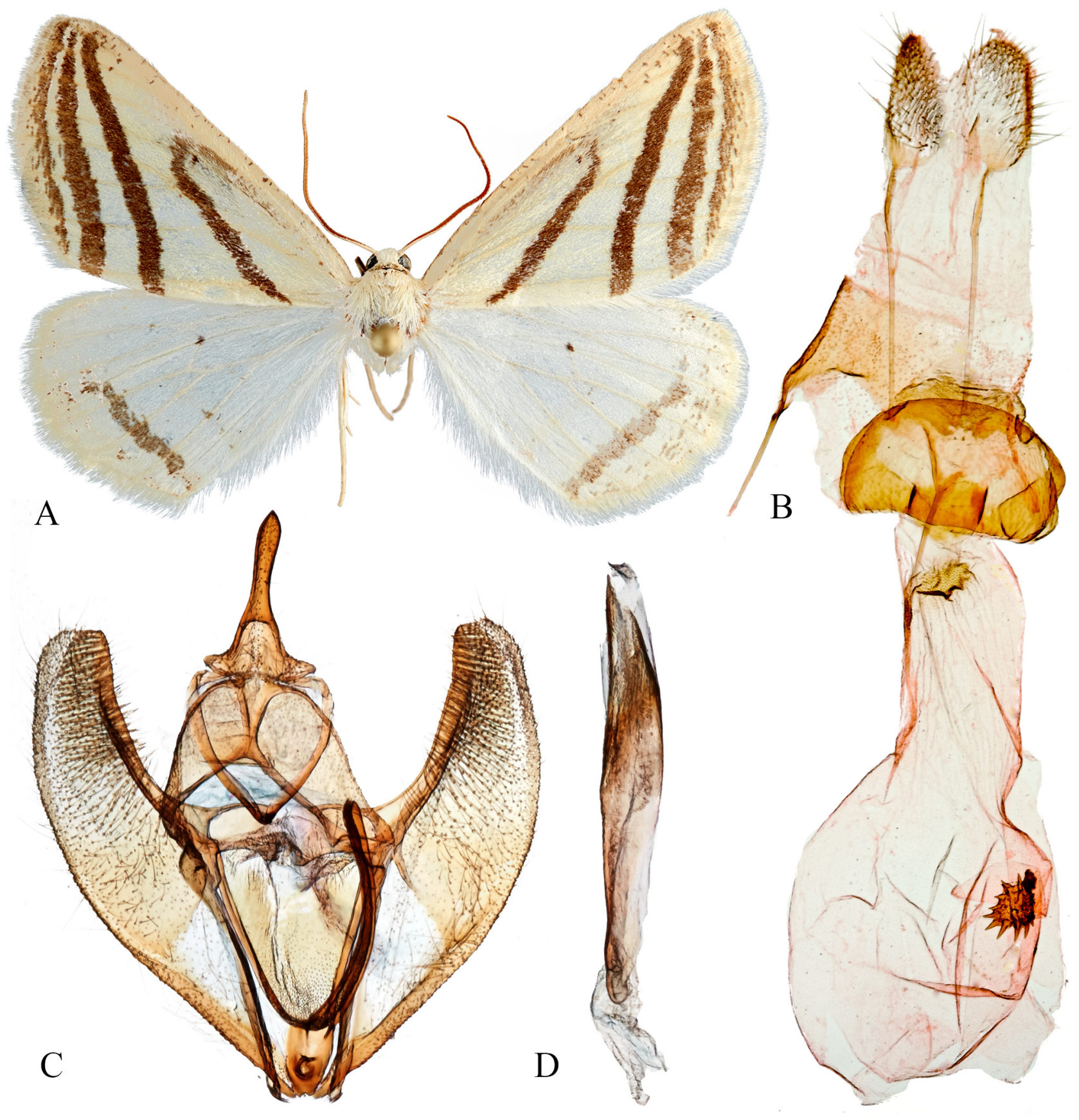

FIGURE 1. Adult Metrica kuschea. A, C, D, USA: AZ: Cochise Co., Chiricahua Mts., Long Park above Rustler Park (FR 42D), Elev. 9160', 30 June 2015, coll. J. Palting, Genetic Voucher(s): DLW-001745, TAM0223, Genitalic Voucher: TAM-2021-098; A, dorsal habitus; B, female genital (PARATYPE), USA: AZ: Cochise Co., Chiricahua Mountains, Turkey Flat, 8-9000', 22 July 1927, coll. J.A. Kusche, USNM 131357; C, male genital capsule; D, male phallus. Images not to scale. 
Description. Adult: (Figs. 1, 5). Head: Antenna filiform. Frons and vertex off-white, finely scaled. Labial palpus short, subequal to diameter of eye. Proboscis well-developed. Chaetosemata well separated. Thorax: Creamcolored. Foreleg with large epiphysis; tibial spur formula 0-2-4; hindtibia swollen, bearing plume of long androconia folded into longitudinal groove on inner surface (when not deployed). Forewing: Cream, darkened along subcostal area, and with four, brown transverse bands located respectively at antemedian, postmedian, subterminus, and outer margin. Antemedial band oblique, running subparallel to costa, diffusing, and hooking basally into darkened subcostal area at median; tiny brown discal spot situated basal to antemedial band in subcostal area. Outer margin band more diffuse and less defined than other bands, especially distally. Some light speckling along costa. Underside concolorous with upperside, but without bands (although banded patterning does show through). Subcostal area noticeably darker and given to brown. Hindwing: Concolorous with forewing. Brown discal dot present on both sides of wing. Upperside variable, but often with subterminal, transverse brown band ending before apex. Light brown speckling often present between subterminal band and outer margin. Abdomen: Cream. Cavi tympani globular, well separated, with ansa stout, swollen at base, narrowing and arcing in distal two-thirds, and flattened at apex. Male genitalia: (Figs. 1C, 1D) $(\mathrm{n}=2)$ Uncus slender, tapering medially to appear slightly spatulate. Arms of gnathos fused mediodistally bearing slight spination. Valve with pronounced costal sclerite spanning entirety of costal margin, costal sclerite inwardly falcate at apex. Anellus weakly sclerotized forming shallow pouch between arms of tegumen; furca (derived from both anellus and juxta) asymmetric, left-directed, one-half length of valve, and bearing apical setae that appear to interact with gnathal lobes; juxta with small digitate cavity directed anteriorly near saccus. Phallus slender with basal digitate heel; without cornuti. Female genitalia: (Fig. 1B) $(n=2)$ Anterior apophysis one-third length of posterior apophysis. Sternite of A8 well sclerotized around ostium bursae, folded transversely to create large ventral flap. Ostium with ventral, transverse triangulate sclerite; ductus bursae short. Corpus bursae pyriform with two signa: first signum situated posterodorsad, near junction with ductus bursae, amorphous, transversely extended, and indented to appear cup-like; second signum as in several related genera, circular, inwardly depressed, positioned anteroventrally, and bearing many inward-directed spines.
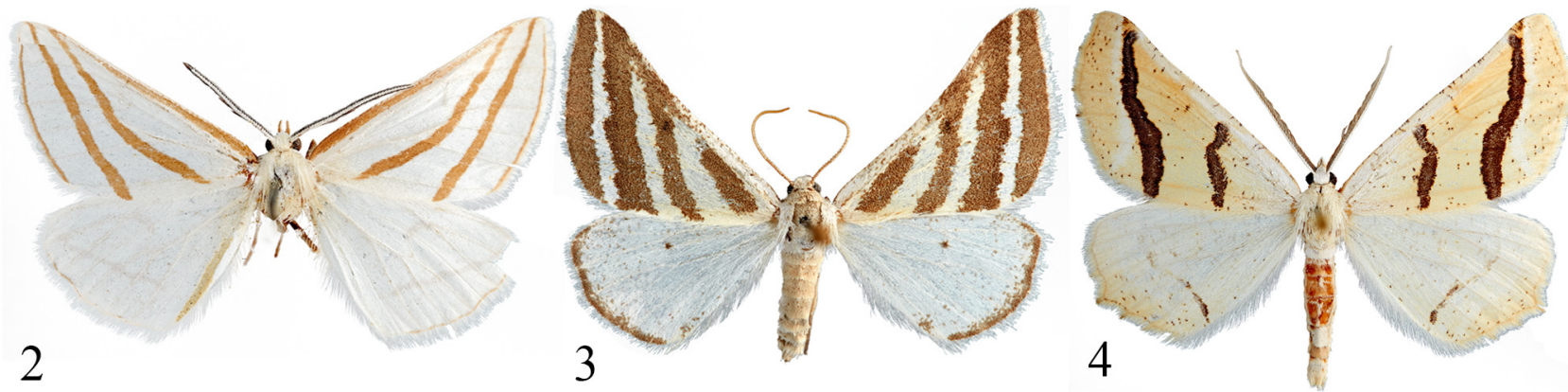

FIGURES 2-4. Dorsal habitus of taxa superficially similar to Metrica but not closely related. 2, Megaspilates mundataria, [Eurasia], location label unintelligible, Genitalia Slide: USNM57223; 3, Euaspilates spinataria, USA: New Mexico: Harding Co., 1mi. S. of Mills Cyn. Campground (036 01' 52.7” N, 104 21'43.2” W), Elev. 5120', 21 July 1998, coll. J.D. Hooper; 4, Eriplatymetra coloradaria, USA: Colorado: Chaffee Co., 4 mi N of Buena Vista, Elev. 8500', 14 July 1982, coll. Douglas C. Ferguson. Images not to scale.

Biology. Metrica kuschea is known only from the high elevations (>8000 ft) of the Chiricahua mountains of southeastern Arizona, USA, but may also inhabit undersampled areas of the northern reaches of Mexico's Sierra Madre Occidental. The taxon is single-brooded with an adult flight centered in June and July in Arizona.

In July of 2016, John Palting of Tucson, Arizona, egged a gravid female of Metrica kuschea that yielded many eggs which were subsequently split between himself and David Wagner (UConn). Neonates were offered a buffet of host options that grow at or near the collection site. Palting offered Abies, Cercocarpus, Holodiscus, Mertensia, Penstemon, Pinus, Populus, Prunus, Ribes, Rosa, and Rubus, all without success. Wagner tried Abies, Amphiachyris dracunculoides, Holodiscus, and Penstemon barbatus, he too, without success.

In July of 2021, John Palting, egged a second gravid female - this time with moderate success as he was able to establish larvae on a potted plant of aspen fleabane (Erigeron speciosus) (Asteraceae), a widespread, native, western North American species found at mid to high elevations in the Chiricahua mountains. The brown caterpillars predominantly fed at night, resting off plant attached to the mesh over his potted plant by day. Unfortunately, no 
larvae were imaged; early instars defoliated John's single plant, and while attempting to garner fresh host foliage, John was stymied by monsoonal floods - all larvae would eventually perish at about one centimeter in length after being switched to spreading fleabane (E. divergens). The immediate hatching of both clutches of eggs suggests that caterpillars typically follow the adult flight with larvae likely present from July through August, and that the pupa overwinters.

If Metrica kuschea proves to be a dietary specialist on Erigeron, it is unlikely that it would feed exclusively on E. speciosus. Several rarer and more geographically limited species of Erigeron may also host $M$. kuschea - perhaps one or more of these species proving to be more preferred. The Chiricahua mountains are home to six native Erigeron species, all of which may co-occur above $8000 \mathrm{ft}$ (Bennett et al. 1996). Ironically, the rarest of these, a high-elevation species restricted exclusively to the Chiricahua mountains, is Erigeron kuschei-yes, like the specific epithet of Metrica kuschea - a patronym to honor the original collector of both species, John August Kusche.

Etymology. The new genus name, Metrica, relates to the geometric lines of the forewing of the only known species, Metrica kuschea, and the geometrid family to which this taxon belongs.

Remarks. Molecular data place Metrica among the Ennomini following the synonymization of the previously recognized Ourapterygini (Beljaev 2008, Sihvonen et al. 2011; Brehm et al. 2019). Metrica shows a well-supported sister relationship to a Neotropical lineage of "Isochromodes" (Figs. 7, 9, see Discussion).
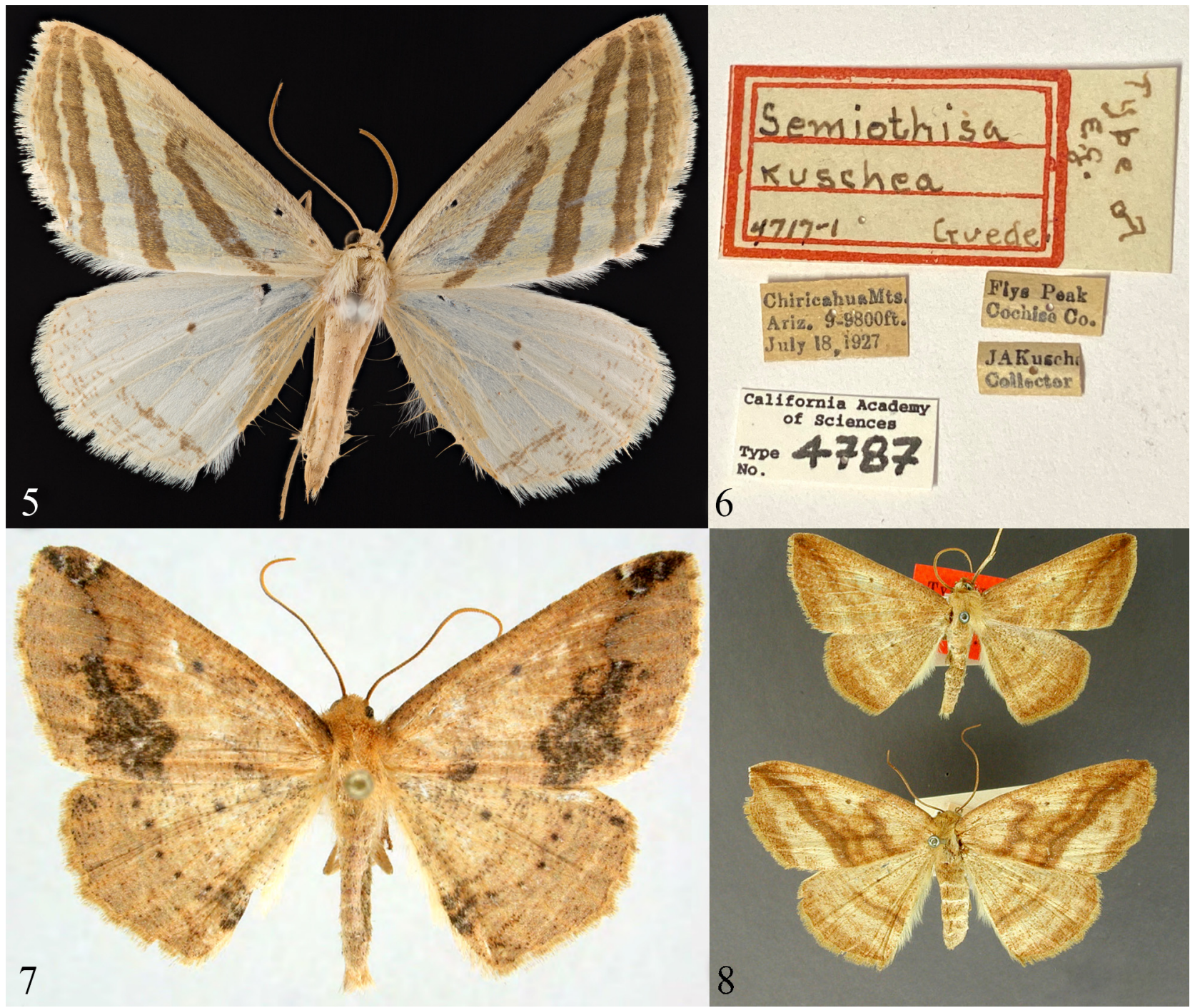

FIGURES 5-8. Type specimen and molecular voucher images. 5, HOLOTYPE male of Semiothisa kuschea, and 6, label data (image credit Chris Grinter); 7, voucher image of "Isochromodes" "infida" (GB-CR-1241), sister taxon of Metrica misidentified as Certima dositheata in Murillo-Ramos et al. (2019) and Brehm et al. (2019) (image taken from, and image credit to, Supplement File 5 of Brehm et al. (2019)); 8, SYNTYPES of Sabulodes infida from USNM type search (https://collections.USNM.si.edu/ search/ento/). Images not to scale. 


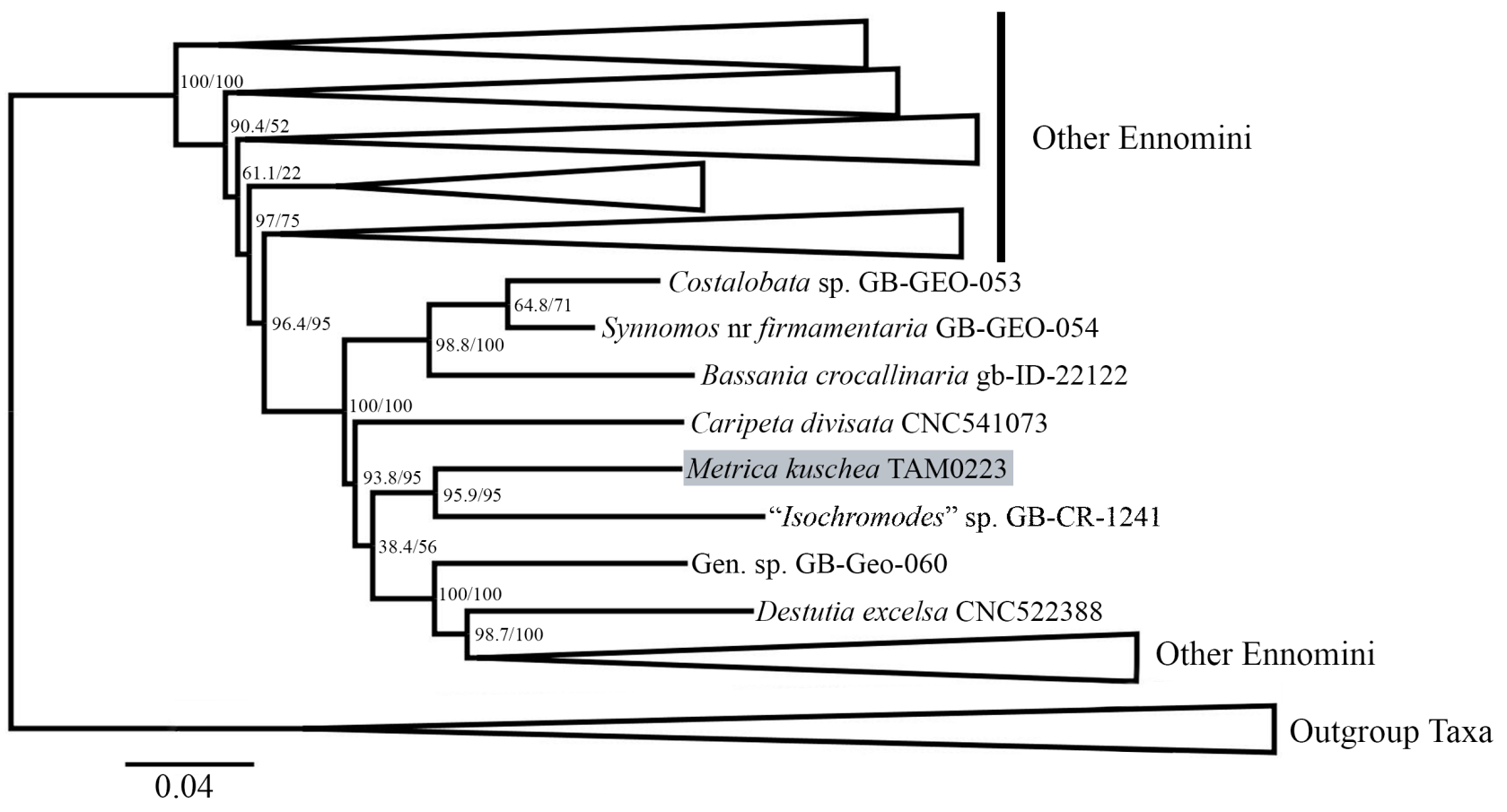

FIGURE 9. Phylogeny of Ennomini genera with voucher IDs from IQ-TREE analysis. SH-like support values are followed by ultrafast bootstrap (UFBoot2) support values.

\section{Discussion}

The identity of Metrica's closest known relative as shown through phylogenetic analyses (Fig. 9) requires much explanation. The sequenced individual used in my analyses for this taxon (Fig. 7) - the same used in the phylogenetic analyses of Murillo-Ramos et al. (2019) and Brehm et al. (2019) and uploaded to GenBank (GBCR-1241) - is misidentified as the visually similar species, Certima dositheata (Guenée). Instead, the sequenced individual matches both in phenotype and DNA barcode (COI) to the currently recognized concept of Isochromodes infida Schaus-however, issues arise here as well. Isochromodes is a highly unnatural genus: the four sequenced representatives of the genus in Brehm et al. (2019) came out in four separate parts of their tree that presumably represent four separate genera, including the misidentified "Isochromodes" infida as Certima dositheata. Pitkin (2002) recognizing the non-monophyly of Isochromodes, excluded infida and several other species from the genus, listing them as "Isochromodes" without generic placement. The sequenced individual of infida (GB-CR-1241) likely belongs to an unnamed genus of Neotropical Ennomini.

To add further confusion, the syntypes of "Isochromodes" infida in the USNM type collection (Fig. 8), do not match the present concept of "I." infida as used in the identified material at the USNM and on the Barcode of Life Project (BOLD) (http://www.boldsystems.org) (Ratnasingham and Hebert 2007) (e.g., where Daniel Janzen has dozens of barcoded individuals from Guanacaste, Costa Rica). In sum, the sequenced individual (Fig. 7, GB-CR1241) - used in the molecular analyses of Murillo-Ramos et al. (2019), Brehm et al. (2019), and the phylogeny shown here (in Fig. 9) appears to represent neither Isochromodes nor the species infida. Despite the ambiguity surrounding the taxonomy of Metrica's sister entity, it is not of critical importance as Metrica is sufficiently different from its sister and other Ennomini to warrant new generic status.

If absent from Mexico, Metrica kuschea may prove to be one of North America's rarest moths and yet another taxon that attests to the high levels of endemism of the Chiricahua Mountains and adjacent Madrean sky islands. Though unmentioned in Wagner et al.'s (2019, Table 1) preliminary list of Chiricahuan, sky island endemic macroLepidoptera, this taxon most certainly belongs among the list, and in the same manner faces elevated extinction risks from climate change and associated fires. Metrica is found only at the highest elevations of the Chiricahuas, where the threat of climate change to local flora and fauna is exacerbated by the fact that these mountaintop-dwelling species will not be able to move up-slope to find climatic refugia. Studies recognizing endemism, working out 
life histories, and documenting the interaction diversity of Madrean sky island lineages (like Metrica) are urgently needed as the American West is drying, annual precipitation patterns are changing, and its climate is becoming increasingly variable.

\section{Acknowledgments}

I am indebted to a host of geometridologists, largely organized through Forum Herbulot, for providing the phylogenetic backbone (Murillo-Ramos et al. 2019, Brehm et al. 2019) that allowed me to confirm and place this new genus. John Palting (Tucson, Arizona) is acknowledged for his continuous support and advocacy for Madrean sky island Lepidoptera. John provided fresh material for the molecular analyses herein, as well as important data concerning the life history of Metrica. Chris Grinter (CAS) contributed images of type material. David Wagner and Héctor Vargas provided helpful suggestions on earlier versions of the manuscript. The author is supported by the University of Connecticut's Ecology and Evolutionary Biology Department's EEB Student Award.

\section{Literature cited}

Beljaev, E. (2008) A new concept of the generic composition of the geometrid moth tribe Ennomini (Lepidoptera, Geometridae) based on functional morphology of the male genitalia. Entomological Review, 88, 50-60. https://doi.org/10.1134/S0013873808010089

Bennett, P.S., Johnson, R.R. \& Kunzmann, M.R. (1996) An Annotated List of Vascular Plants of the Chiricahua Mountains, Including the Pedregosa Mountains, Swisshelm Mountains, Chiricahua National Monument, and Fort Bowie National Historic Site. No. 12. United States Geological Survey, Biological Resources Division, University of Arizona, Tucson, Arizona, $224 \mathrm{pp}$.

Brehm, G., Murillo-Ramos, L., Sihvonen, P., Hausmann, A., Schmidt, B.C., Õunap, E., Moser A., Mörtter, R., Bolt, D., Bodner, F., Lindt, A., Parra, L.E. \& Wahlberg, N. (2019) New World geometrid moths (Lepidoptera: Geometridae): Molecular phylogeny, biogeography, taxonomic updates and description of 11 new tribes. Arthropod Systematics and Phylogeny, 77 (3), 457-486. https://doi.org/10.26049/ASP77-3-2019-5

Ferguson, D.C. (1983) Larentiinae. In: Hodges, R.W., Dominick, T., Davis, D.R., Ferguson, D.C., Franclemont, J.G., Munroe, E.G. \& Powell, J.A. (Eds.), Check List of the Lepidoptera of America North of Mexico. University Press, Cambridge, pp. 101-107

Ferguson, D.C. (2008) Moths of America North of Mexico. Fascicle 17.2. Geometroidea, Geometridae, Ennominae (part: Abaxini, Cassymini, Macariini). Allen Press, Inc., Lawrence, Kansas, 430 pp.

Guedet, E. (1939) Geometrid notes and new species. The Pan-Pacific Entomologist, 15 (1), 33-34.

Guindon, S., Dufayard, J.-F., Lefort, V., Anisimova, M., Hordijk, W. \& Gascuel, O. (2010) New algorithms and methods to estimate maximum-likelihood phylogenies: assessing the performance of PhyML 3.0. Systematic Biology, 59 (3), $307-$ 321. https://doi.org/10.1093/sysbio/syq010

Hoang, D.T., Chernomor, O., von Haeseler, A., Minh, B.Q. \& Vinh, L.S. (2017) UFBoot2: improving the ultrafast bootstrap approximation. Molecular Biology and Evolution, 35 (2), 518-522. https://doi.org/10.1093/molbev/msx281

Inoue, H. (1986) Further new and unrecorded species of the Geometridae from Taiwan with some synonymic notes (Lepidoptera). Bulletin of the Faculty of Domestic Sciences of Otsuma Women's University, 22, 211-267.

Kearse, M., Moir, R., Wilson, A., Stones-Havas, S., Cheung, M., Sturrock, S., Buxton, S., Cooper, A., Markowitz, S., Duran, C., Thierer, T., Ashton, B., Mentjies, P. \& Drummond, A. (2012) Geneious Basic: an integrated and extendable desktop software platform for the organization and analysis of sequence data. Bioinformatics, 28 (12), 1647-1649. https://doi.org/10.1093/bioinformatics/bts199

Lafontaine, J.D. (2004) The Moths of America North of Mexico. Fascicle 27.1. Noctuoidea, Noctuidae (part): Noctuinae, Agrotini. Allen Press, Inc., Lawrence, Kansas, 385 pp.

Larsson, A. (2014) AliView: a fast and lightweight alignment viewer and editor for large datasets. Bioinformatics, 30, 32763278 . https://doi.org/10.1093/bioinformatics/btu531

Miller, M.A., Pfeiffer, W. \& Schwartz, T. (2010) Creating the CIPRES science gateway for inference of large phylogenetic trees. In: Proceedings of the Gateway Computing Environments Workshop (GCE), New Orleans, Louisiana, 2010, pp. 1-8. https://doi.org/10.1109/GCE.2010.5676129

Murillo-Ramos, L.C., Brehm, G., Sihvonen, P., Hausmann, A., Holm, S., Ghanavi, H.R., Õunap, E., Truuverk, A., Staude, H., 
Friedrich, E., Tammaru, T. \& Wahlberg, N. (2019) A comprehensive molecular phylogeny of Geometridae (Lepidoptera) with a focus on enigmatic small subfamilies. PeerJ, 7, e7386.

https://doi.org/10.7717/peerj.7386

Nguyen, L.-T., Schmidt, H.A., von Haeseler, A. \& Minh, B.Q. (2015) IQ-TREE: a fast and effective stochastic algorithm for estimating maximum likelihood phylogenies. Molecular Biology and Evolution, 32 (1), 268-274.

https://doi.org/10.1093/molbev/msu300

Õunap, E., Viidalepp, J. \& Truuverk, A. (2016) Phylogeny of the subfamily Larentiinae (Lepidoptera: Geometridae): integrating molecular data and traditional classifications. Systematic Entomology, 41 (4), 824-843.

https://doi.org/10.1111/syen.12195

Peña, C. \& Malm, T. (2012) VoSeq: a voucher and DNA sequence web application. PloS One, 7 (6), e39071. https://doi.org/10.1371/journal.pone.0039071

Pitkin, L. (2002) Neotropical Ennomine moths: a review of the genera (Lepidoptera: Geometridae). Zoological Journal of the Linnean Society, 135 (2-3), 121-401. https://doi.org/10.1046/j.1096-3642.2002.01200.x

Pohl, G.R., Patterson, B., \& Pelham, J.P. (2016) Annotated taxonomic checklist of the Lepidoptera of North America, North of Mexico. Working paper published online by the authors at ResearchGate.net, $766 \mathrm{pp}$. https://doi.org/10.13140/RG.2.1.2186.3287

Rambaut, A. (2012) Figtree 1.4.4. Available from: http://tree.bio.ed.ac.uk/software/figtree/ (accessed 1 October 2021)

Ratnasingham, S. \& Hebert, P.D. (2007) BOLD: the barcode of life data systems. Molecular Ecology Notes, 7 (3), $355-364$. https://doi.org/10.1111/j.1471-8286.2007.01678.x

Scoble, M.J. (1999) Geometrid Moths of the world: a Catalogue. Vols. 1 and 2. CSIRO Publishing, Collingwood, Australia, $1016 \mathrm{pp}$. https://doi.org/10.1071/9780643101050

Scoble, M.J. \& Krüger, M. (2002) A review of the genera of Macariini with a revised classification of the tribe (Geometridae: Ennominae). Zoological Journal of the Linnean Society, 134 (3), 257-315. https://doi.org/10.1046/j.1096-3642.2002.00008.x

Sihvonen, P., Mutanen, M., Kaila, L., Brehm, G., Hausmann, A. \& Staude, H.S. (2011) Comprehensive molecular sampling yields a robust phylogeny for geometrid moths (Lepidoptera: Geometridae). PLoS One, 6, e20356. https://doi.org//10.1371/journal.pone.0020356

Stamatakis, A. (2014) RAxML version 8: a tool for phylogenetic analysis and post-analysis of large phylogenies. Bioinformatics, $30(9), 1312-1313$. https://doi.org/10.1093/bioinformatics/btu033

Stamatakis, A., Hoover, P. \& Rougemont, J. (2008) A rapid bootstrap algorithm for the RAxML Web servers. Systematic Biology, 57 (5), 758-771. https://doi.org/10.1080/10635150802429642

Wagner, D.L., Palting, J.D. \& Garvey, C. (2019) The Chiricahua Mountains, sky islands and climate change. News of the Lepidopterists'Society, 61 (2), 100-103.

Wahlberg, N., Peña, C., Ahola, M., Wheat, C.W. \& Rota, J. (2016) PCR primers for 30 novel gene regions in the nuclear genomes of Lepidoptera. ZooKeys, 596, 129-141. https://doi.org/10.3897/zookeys.596.8399

Wahlberg, N. \& Wheat, C.W. (2008) Genomic outposts serve the phylogenomic pioneers: designing novel nuclear markers for genomic DNA extractions of Lepidoptera. Systematic Biology, 57 (2), 231-242. https://doi.org/10.1080/10635150802033006 